\section{Sobre "se perder", "vacilar" e não encontrar o "homem certo": mudanças ideacionais, instituições e a fecundidade abaixo do nível de reposição}

\author{
Paula Miranda-Ribeiro* \\ Joseph Earl Potter ${ }^{\star *}$
}

O Brasil, na última década, se juntou ao grupo de países cuja fecundidade está abaixo do nível de reposição. A Taxa de Fecundidade Total (TFT), calculada a partir da PNDS 2006 para 2003-2006, chegou a 1,8 filho por mulher para o total do país, ficando abaixo dos 2,1 filhos (nível de reposição) tanto em áreas urbanas quanto rurais, bem como em todas as grandes regiões do país, com exceção do Norte (MINISTÉRIO DA SAÚDE, 2009).

O caso brasileiro é bastante distinto da maioria dos países europeus ocidentais com fecundidade abaixo do nível de reposição. Nesses últimos, a estrutura etária da fecundidade tornou-se envelhecida, uma vez que as mulheres costumam investir na educação e em suas carreiras profissionais para, posteriormente, decidir sobre a maternidade. $\mathrm{O}$ Brasil, ao contrário, apresenta um padrão de fecundidade jovem, com alta proporção de nascimentos de mães adolescentes e a moda da curva no grupo de 20 a 24 anos. A idade mediana ao primeiro filho, para as mulheres brasileiras de 25 a 29 anos, que estava em torno de 22 anos em 1986 e 1996, diminuiu para 19 anos em 2006, o que significa que metade das mulheres deste grupo etário tornou-se mãe ainda na adolescência (BEMFAM, 1987 e 1997; MINISTÉRIO DA SAÚDE, 2009).

Dois artigos recentes abordam a questão da fecundidade no Brasil. Enquanto Alves e Cavenaghi (2009) mostram as diferenças no nível e padrão da fecundidade segundo educação, renda, participação feminina no mercado de trabalho e classe social, usando dados do Censo 2000 e das PNADs, Potter et al. (2010) estudam o padrão espacial da transição, por meio dos dados dos censos demográficos. Ambos concordam que a velocidade da queda foi mais rápida entre as mulheres pobres e de menor escolaridade, como foi o caso das residentes no interior do Nordeste. $\mathrm{O}$ fato de a fecundidade estar caindo tão drasticamente entre as mulheres pobres e pouco escolarizadas sugere que os fatores socioeconômicos não são suficientes para entender a fecundidade abaixo do nível de reposição no Brasil.

Comparando duas gerações distintas e de baixo nível socioeconômico, o objetivo deste texto é contribuir para o debate, mostrando como fatores ideacionais e institucionais contribuíram para a formação do atual padrão de fecundidade. Além da gravidez propriamente dita, analisam-se, também, a virgindade e o casamento, indicando o papel que o acesso à contracepção, a mídia e a religião parecem ter tido nestas mudanças. As evidências vêm de uma releitura de dados qualitativos coletados pela primeira autora deste texto, em 1996-97, em três comunidades - a cidade de Montes Claros, MG, uma favela na cidade de São Paulo (que chamaremos de Vila Feliz) e uma vila no sertão do Rio Grande do Norte (que chamaremos de Macambira) -, onde foram realizados grupos focais com adolescentes de 14 a 19 anos e mulheres que eram mães de adolescentes.

A comparação entre as duas gerações indica que houve mudanças radicais com respeito à virgindade. Na geração das mães, a mulher deveria iniciar sua vida sexual após o

\footnotetext{
* Professora associada, Departamento de Demografia e Cedeplar, Universidade Federal de Minas Gerais (UFMG).

** Professor, Departamento de Sociologia e Population Research Center, University of Texas at Austin.
} 
casamento e aprender sobre sexo com o marido experiente. A perda da virgindade antes do casamento era sinônimo de "se perder" e aquela que trilhasse este caminho perderia a oportunidade de um "bom casamento", ou, na melhor das hipóteses, teria que se casar com seu primeiro parceiro sexual.

Eu me perdi com 20 anos, só que eu achava que a moça só se perdia quando ela tava, se ela ficasse grávida. Eu me perdi, eu me perdi, me perdi pela cabeça também, porque eu não sabia o que tinha acontecido comigo. (Vila Feliz, mãe)

Na geração dos filhos, a perda da virgindade antes de uma união passou a ser considerada aceitável ou até mesmo desejável. Além disso, outra importante mudança com relação à geração das mães foi a redução da idade em que as mulheres começaram suas vidas sexuais. No entanto, fora de um relacionamento estável e duradouro, a perda da virgindade impôs um custo elevado a muitas adolescentes, chamadas de "galinhas" ou "vagabundas", em oposição às meninas "de família".

Porque aqui, pra moça ter um nome, tem que ser virgem. (Macambira, adolescente)

Algumas vozes, tanto de mães quanto de adolescentes, ainda consideravam a virgindade feminina um valor em si mesmo. Ser virgem era, também, um passaporte com visto de entrada para o casamento.

Eu falo o seguinte: "olha, se você deixar um homem pegar no seu seio, ele vai pegar mais embaixo (...) Se ele pegar mais embaixo, ele vai tentar fazer sexo com você, você fica rapariga". Eu vou dizer logo é assim, sabe, você vai ficar uma meretriz.

Nenhum outro homem não vai te querer. (Vila Feliz, mães)

$\mathrm{Na}$ geração das mães, a expectativa da mulher era se casar e ter filhos. O ideal era que esses eventos seguissem a ordem temporal socialmente estabelecida e que o casamento, feliz, durasse para sempre. Fica claro que muitas delas trilharam este caminho predeterminado, mas houve quem transitasse para a vida adulta de outras formas. Mães solteiras, homens "errados", uniões desfeitas e refeitas e relatos de violência doméstica e de gênero não são exclusividade da geração mais jovem. O caminho alternativo, orgulho para algumas, ainda era motivo de lamento para outras.

(...) eu, que eu sou separada, né, eu, no meu sentido, eu não queria ser uma pessoa separada. (Montes Claros, mãe)

Na segunda metade dos anos 1990, o casamento ainda fazia parte da lista de desejos de muitas adolescentes, mas já tinha deixado de ser a única opção. Ainda assim, tal qual suas mães, muitas jovens, mesmo aquelas que já eram mães, alimentavam o sonho de casar de véu e grinalda e com o "homem certo".

Eu acho que a mulher casar de véu e grinalda, virgem, casar com o homem certo que ela escolheu, é lindo. (Vila Feliz, adolescente)

Apesar do sonho do casamento, entre as adolescentes o ideal romântico de viver feliz para sempre já não valia. Ao contrário, os relatos revelam certa naturalização das separações, apesar do reconhecimento da dor que poderia causar aos filhos. Além disso, havia um misto de descrença, desconfiança e decepção das adolescentes com relação aos homens, sobretudo as que já eram mães. Apesar dos relatos de violência, fica claro que o nível de tolerância das mulheres jovens com relação a parceiros violentos ou abusivos era muito menor do que o de suas mães.

Eu acho que o sonho de toda adolescente, pelo menos mulher, é casar, né? Já eu não... Eu acho que homem só traz problema. (Montes Claros, adolescente)

Uma das grandes mudanças observadas entre as duas gerações diz respeito ao número de filhos desejados. Diferente da geração das mães, várias delas com mais de seis filhos, muitas adolescentes tinham uma meta reprodutiva bastante baixa. As explicações para o desejo de ter poucos filhos estavam ligadas a razões socioeconômicas que iam das dificuldades materiais de sobrevivência ao desejo de oferecer aos filhos uma vida melhor.

Se eu casar um dia, eu quero ter uma filha, ou no máximo dois. Vou lutar, vou dar educação. Quero ver ele formado, quero ver meu filho bem de vida. (Montes Claros, adolescente) 
Paula: E quantos filhos vocês têm vontade de ter?

Eu só quero dois.

Eu também.

É, ter mais de dois...

Mais de dois não.

Um já é difícil, imagine dois. (Macambira, adolescentes)

Entre as adolescentes que já eram mães, muitas haviam abandonado a escola, antes ou durante a gravidez. Em Macambira, algumas mulheres ganhavam a vida com bordado. Nas outras duas localidades, houve poucas referências a trabalho. Além disso, as expectativas com relação ao futuro melhor pareciam limitadas, com exceção de uma única adolescente.

Eu tenho 17 anos, e o meu menino tem 2 meses, tá fazendo agora sexta-feira (...) É, ele chama Gabriel. Bom, eu estudo, eu quero tentar vestibular, principalmente agora por causa do meu filho, que a responsabilidade agora não é só comigo, é com ele também. (Montes Claros, adolescente)

Apesar do número ideal de filhos baixo, a verdade é que a geração mais jovem iniciou mais cedo a sua carreira reprodutiva. Em muitos casos, a gravidez ocorreu pouco tempo depois da primeira relação sexual, senão na primeira vez. Em outros, se deu em idades muito jovens.

(...) tenho 2 filhos (...) Um tem 18 e outro tem 14. Pra começar, o de 14 é pai. (...) É pai. (...) Então o menino mais novo, por mais que eu orientei, por mais que eu dei conselho, ele arrumou uma namoradinha aí, sendo que ela ficou grávida. Agora ganhou neném. Amanhã ela vai fazer 8 dias, tá com 7 dias hoje. É, porque quando eu vou dar conselho, eles fala assim, "ah, mãe, mas a gente tem que começar cedo". Então, no meu tempo não era assim, né, mas eu tenho que respeitar hoje. Mas não é certo, você acha que é justo, uma criança com 14 anos ser pai? Eu não acho, eu mesma não concordo. Mas em todo caso, eu vou fazer o que? Já foi, agora. (Vila feliz, mãe)

Com raras exceções, os relatos mostram que a gravidez na adolescência não era planejada. Ao contrário, era considerada um "vacilo". Caso pudesse voltar no tempo, a maioria das jovens mães teria tido seus filhos mais tarde.

Agora que atualmente, sabe, a coisa mais certa que tem é que, você pode pesquisar em qualquer lugar aí, é você perguntar a uma adolescente ou uma jovem se ela arrumou aquele filho porque ela quis, todo mundo fala, "vacilei". [Paula: É verdade isso?] É verdade.

É verdade porque eu vacilei também. (Montes Claros, adolescentes)

Se a carreira reprodutiva destas jovens começava tão cedo, como é possível ter havido uma queda tão avassaladora da fecundidade? Depois do "vacilo", as adolescentes pareciam determinadas a evitar outra gravidez ou outro nascimento a qualquer custo. Para tal, o mix contraceptivo das jovens incluía, além de pílula e camisinha, o aborto e a esterilização.

Minha irmã, com esse negócio de remédio que não podia tomar e nem camisinha, nem nada, ela abortou 6 filhos, 6 com 18 anos. (Montes Claros, adolescente)

Bom, minhas 3 irmãs conseguiram tirar com Cytotec. Eu tenho 3 irmãs mais velhas do que eu. As 3 já ficaram grávidas, conseguiram. (Vila Feliz, adolescente)

Eu tenho 18 anos (...) Eu tenho dois filhos, um vai fazer quatro anos, só quem fica com ele é minha mãe, quem cria. O outro tem um ano e quatro meses. Já fiz ligação, não posso ter mais. (Macambira, adolescente)

Isso nos leva à primeira das questões institucionais: o acesso à contracepção. Nas três localidades, muitas jovens afirmaram jamais ter usado camisinha, embora, segundo elas mesmas, houvesse disponibilidade do método no posto de saúde. Algumas falaram de dificuldades com a pílula, que deixa "gordinha" ou "nervosa", ou, se for do posto, que "engravida". Fica evidente que a simples oferta de métodos no posto de saúde não era suficiente - conforme Heilborn et al. (2006) já haviam chamado a atenção, se a sexualidade pré-marital feminina é invisível, que dirá a contracepção. Naquele momento, faltava aos jovens educação sexual, posto que o aprendizado sobre questões ligadas a sexo e sexualidade ainda se dava, em grande medida, na rua e com os amigos, com pouca participação das escolas e das famílias, assim como na geração das mães. A grande diferença entre as duas gerações é que, para os jovens, a mídia, em especial a televisão, foi uma importante fonte de informação. 
Assim como antecipado por Faria (1989) duas décadas atrás, não resta dúvida de que a televisão teve um papel fundamental nas mudanças ideacionais ocorridas entre as duas gerações, com destaque para as novelas, cujas tramas, reflexo de comportamentos e atitudes mais afeitos à classe média-alta de grandes centros urbanos e recheadas de mensagens com conteúdo sexual, invadem, sem distinção, todos os domicílios do país. A influência das novelas, para além do linguajar e da moda, é oferecer situações que, ainda que não sejam aceitas, passam a fazer parte do universo das possibilidades. A nossa pesquisa, um estudo de recepção realizado na época em que estava no ar a novela das oito $O$ Rei do Gado, tem inúmeras evidências do papel das novelas nas mudanças ideacionais (ALMEIDA, 2003; HAMBURGER, 2005; LA PASTINA, 2003), bem como do descontentamento de ambas as gerações com o excesso de sexo na televisão, em geral, e nas novelas, em particular.

Acho que [novela] fala um pouco da vida, mostra um pouco da vida de algumas pessoas, às vezes da gente. [Paula: É?] É, mas tem muita coisa ali que não devia passar, né. [Paula: É? Por exemplo?] Que as crianças assim, tem criança que assiste novela, tem muita bobagem, muito sexo, as crianças já crescem aprendendo aquilo, né, é uma coisa que devia cortar da novela. (Vila Feliz, adolescente)

(...) eu não assisto muito bem a novela, não. Mas por exemplo, em relação a sexo, de fazer papel de matar, essas coisas, na novela eu tiraria. (...) É muito pesado pra criança. (Montes Claros, mãe)

Somava-se a isso a dificuldade das mães nestas três comunidades em "prender" suas filhas em casa, uma vez que muitas delas, trabalhadoras, ficavam o dia todo fora e o Estado, ausente, não oferecia nenhum tipo de cuidado no horário alternativo à escola. Assim, crianças e adolescentes ficavam sem supervisão de um adulto durante boa parte do dia, com liberdade para ir e vir e para fazer o que quisessem.
$E$ eu, mesmo que eu quisesse prender a Lívia, eu não tenho, porque a Lívia desde os sete anos que ela fica em casa sozinha, porque eu trabalho de $2^{a}$ a sábado. (Vila Feliz, mãe)

Além das tentativas (nem sempre bem-sucedidas) de algumas famílias, a única instituição que exercia alguma força contrária à intensidade das mudanças ideacionais naquele momento era a religião. As vozes de mães e de adolescentes com forte envolvimento religioso destoavam das demais na tentativa de preservar os valores do passado.

Novela influencia principalmente os jovens. Porque apesar de ser jovem, eu tenho assim, um conhecimento assim, de Deus, da Bíblia e tal, né. Mas tem jovens que não ligam pra nada, tem jovem que só quer... só quer viver pra lá, não quer saber de nada. (Montes Claros, adolescente)

As minhas [filhas] graças a Deus que é de casa pro colégio, do colégio pra casa, e da casa pra igreja, que elas têm religião, né. (...) graças a Deus que nunca na vida elas não tavam se perdendo num baile, numa festa, nem de aniversário. (...) A mais nova ainda vai assim, né, se eu for. A mais velha, agora, chegou o domingo ou o sábado, ela tá arrumadinha pra ir pra igreja. Se eu disser não vai, [ela pergunta]: "e pra onde é que eu vou? Eu não vou pra lugar nenhum. Se eu não for pra igreja..." Às vezes o pai dela [fala]: "não, se elas não forem pra igreja, elas vão pra onde?” (...) Não adianta dizer "Vai", eu não vou empurrar elas pra ir num baile, vou não. Nunca, de jeito nenhum. (Vila Feliz, mãe)

Pensando na história da transição da fecundidade no Brasil, este foi um capítulo triste, no qual as adolescentes pobres, já livres do fantasma de "se perder" e sem a obrigação de encontrar o "homem certo", ainda "vacilavam". Mais triste ainda foi constatar que as políticas sociais também "vacilaram" ao não oferecer a elas educação, informação, contracepção e as oportunidades de vida que elas mereciam. No entanto, é inegável que esta combinação, ainda que trágica, contribuiu para a fecundidade abaixo do nível de reposição no Brasil. 


\section{Referências}

ALMEIDA, H. B. Telenovela, consumo e gênero: "Muitas mais coisas". Bauru: Edusc, 2003.

ALVES; J. E. D.; CAVENAGHI, S. M. Timing of childbearing in low fertility regimes: how and why Brazil is different? In: XXVI IUSSP INTERNATIONAL POPULATION CONFERENCE. Anais... Marrakesh, Marrocos, 27 de setembro a 2 de outubro de 2009. Disponível em: <http:// iussp2009. princeton.edu/download. aspx?submissionld $=92527>$.

BEMFAM - Sociedade Civil Bem-Estar Familiar no Brasil/Macro. Pesquisa Nacional sobre Demografia e Saúde. Brasil 1996. Rio de Janeiro: Bemfam, 1997.

Pesquisa Nacional sobre Saúde Materno Infantil e Planejamento Familiar no Brasil - 1986. Rio de Janeiro: Bemfam, 1987.

FARIA, V. E. Políticas de governo e regulação da fecundidade: consequências não antecipadas e efeitos perversos. Ciências Sociais Hoje, p. 62-103, 1989.

HAMBURGER, E. I. O Brasil antenado. A sociedade das Novelas. Rio de Janeiro: Jorge Zahar Editor, 2005.
HEILBORN, M. L.; AQUINO, E. M. L.; KNAUTH, D. R.; BOZON, M. (Orgs.). O aprendizado da sexualidade: reprodução e trajetórias sociais de jovens brasileiros. Rio de Janeiro: Garamond, 2006.

LA PASTINA, A. Now that you going home are you going to write about the natives you studied? Telenovela reception, adultery and the dilemmas of ethnographic practice. In: MURPHY, P.; KRADY, M. (Eds.). Global media studies. London: Routledge, 2003, p. 186-220.

MINISTÉRIO DA SAÚDE. Pesquisa Nacional de Demografia e Saúde da Criança e da Mulher - PNDS 2006: dimensões do processo reprodutivo e da saúde da criança. Brasília, 2009. Disponível em: <http:// bvsms.saude.gov.br/bvs/publicacoes/ pnds_crianca_mulher.pdf $>$.

POTTER, J. E.; SCHMERTMANN, C. P.; ASSUNÇÃO, R. M.; CAVENAGHI, S. M. Mapping the timing, pace, and scale of the fertility transition in Brazil. Population and Development Review, 36 (2), junho 2010 (no prelo).

Recebido para publicação em 10/05/2010 Aceito para publicação em 20/05/2010 